\title{
Macro- and micro-morphological characteristics of Plantago seeds and its implication for species identification
}

\author{
Ashutosh Kumar Verma ${ }^{1 *}$, Neelam Gautam 1 , Kumar Avinash Bharti \\ ${ }^{1}$ Botanical Survey of India, Central Regional Center, Allahabad, Uttar Pradesh, India-211002, ${ }^{2}$ Botanical Survey of India, Central \\ National Herbarium, AJC Bose Indian Botanic Garden, Howrah, West Bengal, India-711103
}

Received: 31.05 .2017

Accepted: 28.08 .2017

Published: 30.08.2017

*Address for correspondence:

Ashutosh Kumar Verma,

Botanical Survey of India,

Central Regional Center,

10-Chatham Line, Allahabad,

Uttar Pradesh, India.

E-mail:simashutosh@

rediffmail.com

\begin{abstract}
Seed morphology of five species of Plantago (Plantago psyllium, Plantago vate, Plantago lanceolata, Plantago major, and Plantago arenaria) was examined under magnifying glass, compound microscope and scanning electron microscope. Macro- and micro-morphological characters, including seed shape, color, size, shape of cavity, surface ornamentation, and epidermal cell shape are presented. Marked difference among the species noted with respect of considered traits and a key for the identification of the investigated taxa based on seed characters is provided.
\end{abstract}

KEY WORDS: Plantago, Seed coat, scanning electron microscope

\section{INTRODUCTION}

The seed coat (testa) derived from the outer and inner integuments of the ovule, composed of a palisade layer, layers of crushed parenchyma cells, and a single layer of aleurone cells, is a multifunctional organ that plays vital roles in embryo nutrition during seed development, and in protection against various biotic and abiotic stresses afterward (Mohamed-Yasseen et al., 1994; Weber et al., 1996). Based on morphological and anatomical studies, (Sulaiman, 1995; Beeckman et al., 2000) seed coat morphology is known to be an excellent character for taxonomic and evolutionary studies (Vaughan and Whitehouse, 1971; Algan and Büyükkartal, 2000; Zou et al., 2001). At present, seed coat patterns have been used for various purposes: to solve classification problems, to establish evolutionary relationships, to elucidate the adaptive significance of the seed coat, and to serve as genetic markers for the identification of genotypes in segregating hybrid progenies (Lersten, 1979; Gopinathan and Babu, 1985; Rejdali, 1990). Thus, understanding its structure and development has been an important goal for workers and its worth increased for persons who deal with taxonomy and phylogeny of species.
Plantago, a monogeneric to family Plantaginaceae consist of 200 species worldwide (Rahn, 1996; Haddadian et al., 2014). Seeds of these species are used for treatment of chronic constipation, dysentery, abdominal pain, piles, and rheumatism. Now, its potential to lowering cholesterol level also has also been documented (Husain et al., 2008). Because of its immense importance in remedial field, increased market demand, use of allied species as adulterant, there is need for identifying characteristics of the seeds of Plantago species. Therefore, an effort has been made for similar objective.

\section{MATERIALS AND METHODS}

Seeds of five species of Plantago, namely, Plantago psyllium L., Plantago ovata Forssk., Plantago lanceolata L., Plantago major L. and Plantago arenaria Waldst. \& Kit, were procured from various resources of India and their seed coat morphology was worked out in terms of shape, size, surface appearance, and pattern of cavity, etc., using magnifying glass, compound microscope and scanning electron microscope (SEM). For SEM sample preparation, first healthy dried seeds of the mentioned species were selected and placed on double-sided adhesive tape, followed by thin layer coating of gold using ion sputtering. For each 
sample, photographs of micro-sculptures were taken using QUANTO 200, FEI 500 SEM. The anterior and posterior surface was examined at various magnifications, namely, $\times 40, \times 60, \times 150$, and $\times 2500$. The terminology of seed coat microcharacters in our present study was adopted from the descriptions used by Stearn (1966) and Barthlott (1981). For the study of similarity between species/ linkage between species, phenotypic data of species were entered into binary matrix as discrete variable (1) for the presence of phenotypic character and ( 0 ) for the absence of phenotypic character and this matrix were subjected to further analysis. Scores of individual phenotypic character were used to create data matrix. A dendrogram constructed based on Nei and Li's coefficient with unweighted pair group method and arithmetic average analysis (UPGMA) using Fig Tree Version 1.3.1 software.

\section{RESULTS}

In our experiment, variation in seed coat color was recorded. P. ovata which is more economically important among the considered species shared a unique seed coat color and also being the largest in terms of seed dimensions $(2.89 \pm 0.24 \times 1.29 \pm 0.03 \mathrm{~mm})$. In all the species, the shape of cavity present on concave surface was variable.

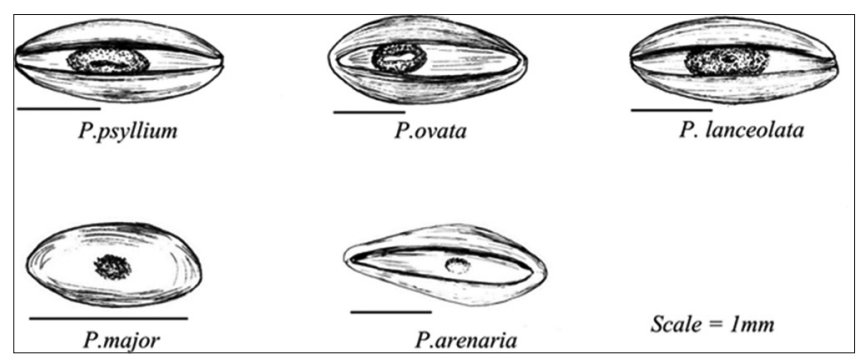

Figure 1: Line diagram of seeds of Plantago species
Bottle-shaped cavity with a flattened edge and naviculoid cavity with flattened edge was found in P. arenaria and P. ovata, respectively. Elliptic cavity with round edges was observed in P. lanceolata and P. psyllium while cavity in P. major was shallower and shared flattened edges. Regular scalariform to reticulate seed coat ornamentation with angular cells were found in all species except for P. major, that shared tuberculate type of ornamentation (Figure 1). The angular cell dimension was highest for P. ovata (62.67 \pm $2.89 \times 39.33 \pm 0.88 \mu \mathrm{m})$ and lowest for P. psyllium (45.33 $\pm 1.52 \times 27.67 \pm 0.58 \mu \mathrm{m})$. Under high magnification $(\times 2500)$ spindle shaped striations in P. lanceolata and rosette pattern of dark patches in seed coat $P$. ovata were observed and noted as unique feature (Table 1). UPGMA cluster analysis of all five species results a dendrogram that divided species into two main clusters: The first comprised P. psyllum, P. lanceolata and P. major and second comprised of P. ovata and P. arenaria (Table 2, Figures 2 and 3).

On the basis of observations for authentic identification of seeds of considered species a bracketed dichotomous key was constructed.

1a. Seed shape oval

1b. Seed shape elliptical

2a. Presence of rosette pattern of unique dark patches on seed coat the surface P. ovata

$2 b$. Absence of unequal dark patches on seed coat

P. psyllium

3a. Angular cell shape pattern forms the surface ornamentation

3b. Non-angular cell shape pattern forms the surface ornamentation

P. major

Table 1: Seed phenology of five Plantago species

\begin{tabular}{|c|c|c|c|c|c|}
\hline \multirow[t]{2}{*}{ Seed traits } & \multicolumn{5}{|l|}{ Name of species } \\
\hline & P. psyllium & P. ovata & P. lanceolata & P. major & P. arenaria \\
\hline Seed color & Brown-to-dark brown & Whitish pinkish light brown & Copper brown & Black & Brownish black \\
\hline Seed shape & Oval & Oval & Elliptical & Elliptical & Elliptical \\
\hline Seed length (mm) & $2.63 \pm 0.04$ & $2.89 \pm 0.24$ & $2.39 \pm 0.01$ & $1.45 \pm 0.03$ & $2.29 \pm 0.13$ \\
\hline Seed breadth (mm) & $1.24 \pm 0.03$ & $1.29 \pm 0.03$ & $1.06 \pm 0.11$ & $0.74 \pm 0.04$ & $0.97 \pm 0.08$ \\
\hline Position of mucilage pore & Median & Sub-median & Median & Median & Sub-median \\
\hline Mucilaginous behavior of seeds & Heavy & Heavy & Moderate & Mild & Mild \\
\hline Cavity shape & Elliptic & Naviculoid & Elliptic & Elliptic & Bottle shaped \\
\hline Nature of cavity & Broad & Narrow & Broad & Narrow & Narrow \\
\hline Nature of cavity edges & Rounded & Flattened & Rounded & Flattened & Flattened \\
\hline Overall seed coat pattern & Scalariform to reticulate & Reticulate to sclariform & Scalariform to reticulate & Tuberculate & Scalariform \\
\hline Seed coat cell shape & Angular & Angular & Angular & Irregular & Rectangular \\
\hline Length of seed coat cell $(\mu \mathrm{m})$ & $45.33 \pm 1.52$ & $62.67 \pm 2.89$ & $50.67 \pm 1.15$ & - & $58.67 \pm 0.67$ \\
\hline Breadth of seed coat cell $(\mu \mathrm{m})$ & $27.67 \pm 0.58$ & $39.33 \pm 0.88$ & $29.00 \pm 1.02$ & - & $32.33 \pm 0.57$ \\
\hline $\begin{array}{l}\text { Striations/other unique } \\
\text { ornamentations of seed coat }\end{array}$ & - & Black-colored resettle patches & Spindle shaped striations & - & - \\
\hline
\end{tabular}



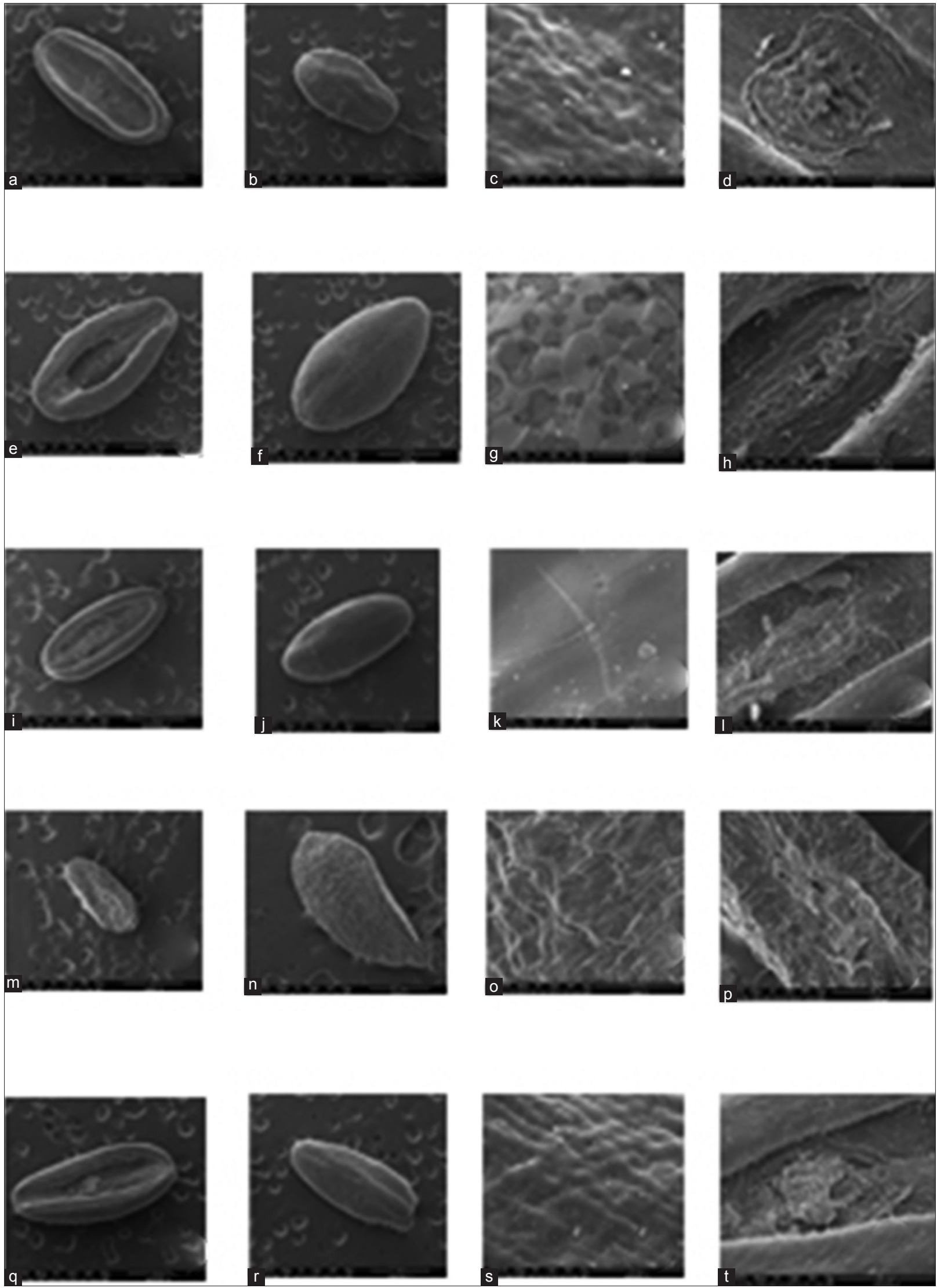

Figure 2: (a-d) Plantago psyllium; (e-h) Plantago ovata; (i-l) Plantago lanceolata; (m-p) Plantago major, (q-t) Plantago arenaria 


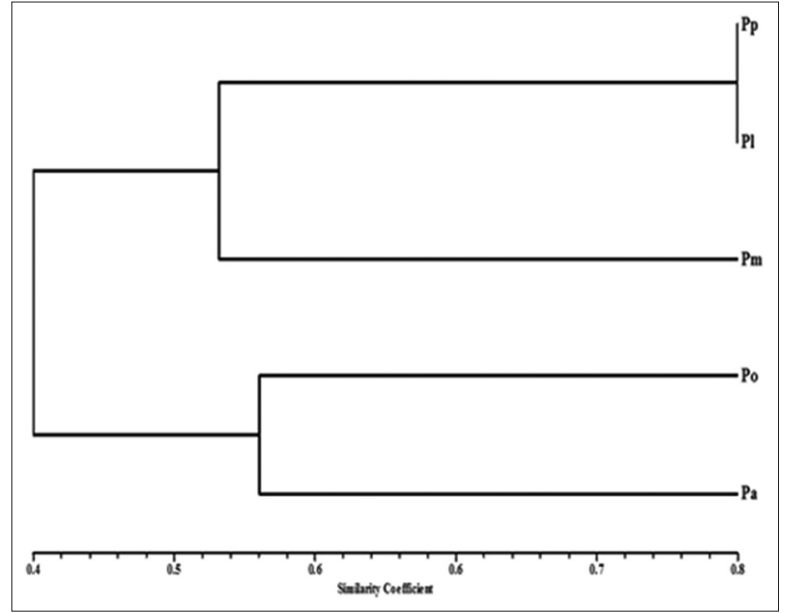

Figure 3: Dendrogram of five Plantago species based on similarity matrix $(P p=P$. psyllium, $P l=P$. lanceolata, $P m=P$. major, $P o=P$. ovata $; P a=P$. arenaria)

Table 2: Similarity matrix of five Plantago species based on seed phenology

\begin{tabular}{lcccc}
\hline Plant species & P. psyllium & P. ovata & P. lanceolata & P. arenaria \\
\hline P. psyllium & 1.00 & & & \\
P. ovata & 0.67 & 1.00 & & \\
P. lanceolata & 0.15 & 0.00 & 1.00 & \\
P. major & 0.13 & 0.10 & 0.26 & 1.00 \\
P. arenaria & 0.00 & 0.26 & 0.53 & 0.44 \\
\hline
\end{tabular}

4a. Narrow, bottle-shaped cavity with flattened edge

P. arenaria

4b. Broad, elliptic cavity with rounded edge

P. lanceolata

\section{DISCUSSION}

The study of fruit, seed, and leaf surface pattern using SEM can be useful taxonomic characteristics for different families and genera (Kumar et al., 2012; Shavvon et al., 2012; Akcin et al., 2013). Shalabi and Abou-EL-Enain (2013) stated that Plantago is a problematic genus; most of the species are closely similar so discovering stable aspects of variation among them is not easy. According to Liu et al. (1992), seed morphology and seed coat structures exhibit specific characters by which some confused species can be clarified. For identification of plantago species characters such as seed surface pattern, seed color, and seed size were considered by earlier workers (Rezk, 1987; Kamel, 2003; Liu et al., 1992; Shehata and Lautfy, 2006).

The reticulate to scalariform surface pattern is quite common among the considered species but in P. major tuberculate non-angular surface pattern which could be defining character for this species. The seed surface of $P$. ovata and $P$. lanceolata showed unique patches and striations, respectively, possible key characters for respective species. Earlier workers performed seed coat study in Plantago species but as per our concern, none of them reported the above-mentioned key characters for P. ovata and P. lanceolata. Our observations based on concave surface cavity were in consonance with the finding of Youngken (1935) in the seeds of P. psyllium and P. arenaria. Shehata and Loutfy (2006) reported that $P$. arenaria and $P$. ovata shares good relationship in terms of seed coat characteristics, contrary to them in our findings, variations were observed in seed coat appearance at micromorphological level. Results of cluster analysis based on similarity matrix of seed phenology (Table 2, Figure 3) were showed agreement the finding of earlier workers as P. ovata and P. arenaria, P. lanceolata, and P. major belongs to same cluster and first to species have highest affinity with each other (Shehata and Loutfy, 2006).

Although the present study is not sufficient for seed identification on the basis of macro-morphological characters but can be helpful in species identification on the basis of micro-morphological seed coat characters. In conclusion, experimental findings again revalidate the scope of seed micro-morphological studies for the development of species specific marker keys and will be helpful in identification of economically important seeds at market and laboratory level.

\section{ACKNOWLEDGMENT}

Authors of the manuscript are grateful to The Director, Botanical Survey of India, Kolkata; Head of Office, Central National Herbarium, AJC Bose Indian Botanic Garden, Howrah, for their kind support and providing necessary facilities during the course of present investigation.

\section{REFERENCES}

Akcin OE, Senel G, Akcin Y. Leaf epidermis morphology of some Onosma (Boraginaceae) species from Turkey. Turk J Bot 2013;37:55-64.

Algan G, Büyükkartal HN. Ultrastructure of seed coat development in the natural tetraploid Trifolium pratense $\mathrm{L}$. J Agron Crop Sci 2000;184:205-13.

Barthlott W. Epidermal and seed surface characters of plants: Systematic applicability and some evolutionary aspects. Nord J Bot 1981;1:345-55.

Beeckman T, de Rycke R, Viane R, Inzé D. Histological study of seed coat development in Arabidopsis thaliana. J Plant Res 2000;113:139-48.

Gopinathan MC, Babu CR. Structural diversity and its adaptive significance in seeds of Vigna minima (Roxb.) Ohwi and 
Ohashi and its allies (Leguminosae-Papilionoideae). Ann Bot 1985;56:723-32.

Haddadian K, Katayoon H, Mohsen Z. A review of Plantago plant. Indian J Tradit Knowl 2014;13:681-5.

Husain SZ, Malik RN, Javaid M, Bibi S. Ethonobotanical properties and uses of medicinal plants of Morgah biodiversity park, Rawalpindi. Pak J Bot 2008;40:1897-911.

Kamel WM. Plantaginaceae in the flora of Egypt: 2. Taxonomic significance of seed characters. Taeckholmia 2003;23:97-110.

Kumar V, Kodandaramaiah J, Rajan MV. Leaf and anatomical traits in relation to physiological characteristics in mulberry (Morus sp.) cultivars. Turk J Bot 2012;36:683-9.

Lersten NR. A distinctive seed coat pattern in the Viceaceae (Papilionoideae, Leguminoseae). Proc Iowa Acad Sci 1979;86:102-4.

Liu JZ, Zhang QM, Guo SH, Zhou XD. Seed morphology of Plantago in China and its taxonomic significance. Acta Phytotaxonomica Sin 1992;30:118-25.

Mohamed-Yasseen Y, Barringer SA, Splittstoesser WE, Costanza $S$. The role of seed coats in seed viability. Bot Rev 1994;60:426-39.

Rahn K. A phylogenetic study of the Plantaginaceae. Bot J Linn Soc 1996;120:145-98.

Rejdali M. Seed morphology and taxonomy of the North African species of Sideritis L. (Lamiaceae). Bot J Linn Soc 1990;103:317-24.
Rezk MR. Variation in seed coat microsculpture in five species of Plantago. Alex Sci Exch 1987;8:57-71.

Shalabi LF, Abou-EL-Enain MM. Morphological variations and morphometry in the genus Plantago. Int J Chem Environ Biol Sci 2013;1:468-72.

Shavvon RS, Shahryar SM, Narges G. Evidence from micromorphology and gross morphology of the genus Loranthus (Loranthaceae) in Iran. Turk J Bot 2012;36:655-66.

Shehata AA, Loutfy MH. On the taxonomy of Plantaginaceae Juss. Sensu Lato: Evidence from SEM of the seed coat. Turk J Bot 2006;30:71-84.

Stearn WT. Botanical Latin. London: Nelson and Sons; 1966. p. 506-7.

Sulaiman IM. Scanning electron microscopic studies on seed coat patterns of endangered Himalayan species of Meconopsis (Papaveraceae). Ann Bot 1995;76:323-6.

Vaughan JG, Whitehouse JM. Seed structure and the taxonomy of the Cruciferae. Bot J Linn Soc 1971;64:383-409.

Weber H, Borisjuk L, Wobus U. Controlling seed development and seed size in Vicia faba: A role for seed coat associated invertases and carbohydrate state. Plant J 1996;10:823-34.

Youngken HW. Further studies on psyllium seed. J Am Pharm Asso 1935;24:207-11.

Zou X, Foutain DW, Morgan ER. Anatomical and morphological studies of seed development in Sandersonia aurantiaca Hook. S Afr J Bot 2001;67:183-92. 